\title{
R\&D Spending and Economic Growth in Selected OECD Countries
}

\section{Arash Ketabforoush Badri ${ }^{1^{*}}$ \\ Parsa Ketabforoush Badri ${ }^{2}$ \\ Mostafa Cham ${ }^{s}$}

\begin{abstract}
$R \Theta D$ is one of the important factors affecting economic growth. Increased use of $R \Xi^{D} D$ will increase competition in manufacturing sectors, which will have a positive impact on the economy, improving product quality and diversity and improving productivity, which will increase production itself. The purpose of this study is to investigate the effects of RछD spending on economic growth using the GMM method for the 15 selected OECD countries from 2012 to 2018. The estimation results show that $R E D$ has had a positive and significant effect on economic growth in the countries studied. Also, GDP of the last year, exchange rate and tax have had a positive impact on economic growth.
\end{abstract}

This work is licensed under a Creative Commons Attribution 4.0 License.

Keywords:

$R \Theta^{2} D$ spending

Economic growth

GMM method.

JEL Classification:

O30; 032 ; 040.

Accepted: 8 October 2019

Published: 29 October 2019

Funding: This study received no specific financial support.

Competing Interests: The authors declare that they have no competing interests.

\section{Introduction}

One of the most important strategies that sustains firms is to strengthen the power of innovation to create and use advanced technology to produce products and do more effective work to meet the needs of the society (Hunermund \& Czarnitzki, 2019).

Economists believe that science and technology, as an effective and powerful tool, can play a key role in the development process. In today's world, countries are among the developed countries that have high level of science and technology. Therefore, many of the advanced products, methods, tools and technologies are the result of the development of these countries in science and technology (Bazdar, 2011).

In today's world, communications, commodities, information and technology have expanded and improved over the past. Producers and exporters of the commodities have had a better opportunity than ever before to compete in these international markets and thereby expand their scope. The most traditional way to enter these markets, i.e. export of goods, has led to greater and wider development, more revenue, and continuous awareness of the latest technological and knowledge developments than ever before (Ketabforoush, Yahyavi, \& Pourebrahim, 2015).

The high standard of living, advanced land, sea and air transportation and health conditions in developed countries are a direct result of increased research and development costs in these countries, so that industrialized countries have a significant share of their income and labor force. They devote themselves to $\mathrm{R} \& \mathrm{D}$ activities. Investing in $\mathrm{R} \& \mathrm{D}$ and using new technologies will increase productivity, reduce costs, improve production structure and export growth. Advancement of various technologies will increase production efficiency and increase product diversification, which will reduce relative cost of production and increase the relative advantage of firms and ultimately increase export and income of the country (Ketabforoush, Dizaji, Salavati, \& Gholami, 2013). 
Technological development and investment in R\&D activities is an important determinant of exports. The costs of $\mathrm{R} \& \mathrm{D}$ and investment in this area increase creativity and the emergence of new production ideas and provides conditions for businesses to increase their productivity; which increases capacity, reduces costs and increases productivity. The quality of the products, and ultimately the export, will increase (Molayi \& Dehghani, 2011).

To this end, the present study attempts to investigate the effects of R\&D on the economic growth of 15 selected OECD countries from 2012 to 2018 using the GMM method.

\section{Theoretical Foundations and Previous Studies}

Today, $\mathrm{R} \& \mathrm{D}$ is the key to compete with the world's modern technologies and plays a major role in innovation, productivity growth and economic growth. The difference between the growth rates of countries and their persistence or instability is a topic that has been explained in various ways by growth theories. Among these theories can be targeted innovations (Schumpeter, 1934) exogenous technology changes (Solow, 1956) in-service training (Arrow, 1962) human capital accumulation rates (Lucas, 1988) human births (Becker, Murphy, \& Tamura, 1990) levels of government spending (Barro, 1990) R\&D (Romer, 1990) International Trade (Grossmen \& Helpman, 1989) etc., who have attempted to explain the differences between countries in different periods of time. Here's a brief overview of these theories.

Schumpeter (1934) with a view to the driving force within the capitalist system, has done his research. The competition among entrepreneurs for developing a new production method or offering a new product encourages them, as a targeted broker, to devote their resources to creating a new initial design or a combination of the data needed to produce the product at a lower cost. Or, more importantly, spend on developing a completely new product. Rosenberg (1982) in explaining Schumpeter's theory of the destruction of creativity, argues that creativity must be commensurate with the revolution in that sector. For example, the improvement and efficiency of horse riding production will never lead to a revolution in the transportation sector, but rather to the creation of completely new modes of transport such as railroads and cars that are suited to this revolution. It is a dynamic process of targeted innovation that follows the "creative destruction" hailstorms that Schumpeter considers to be right for economic growth. Schumpeter's Theory of targeted Inventions (Schumpeter, 1934) was later formally formulated by Aghion and Howitt (1992); Aghions and Howitt (1998).

Solow (1956) is a basic model for economic growth analysis that analyzes the process of economic growth. In a poor economy there is very little capital available to work, so the rate of return on capital is very high. This encourages people to have more savings and investment, as a result the economy is on the path to growth and development, as more capital accumulates, investment returns decrease, and thus people reduce their savings and investments to the accumulation process. It goes where society gets the desired capital and product. The most important application of the neoclassical model is the convergence hypothesis. Assuming that both groups of poor and rich countries have the same technology in place, but poorer countries are growing at a faster rate than the rich ones. This will ensure that in long-term all economies will have the same amount of capital and production convergence. Thus, the initial status of an economy has no role in determining the abundance of wealth in an economy in long-term (Shakeri \& Ebrahimi, 2009).

$\mathrm{R} \& \mathrm{D}$ is a major driver of innovation and technical change in the production process, and therefore plays an important role in enhancing the productivity of the society or economic growth. To illustrate this role, a nonlinear production function model based on the theoretical form of the Cobb-Douglas function is used. In these models, the technological process results from research and innovation and the discovery of new technologies increases productivity and such discoveries are ultimately the source of long-term growth. The main equations of these models are as follows Equation 1 and Equation 2:

$$
\begin{aligned}
& Y=K^{\alpha}\left(A L_{y}\right)^{\beta} \\
& \frac{A}{A}=\delta L_{A}
\end{aligned}
$$

As can be seen in Equation 1 in the above, $\mathrm{Y}$ is the product, $\mathrm{A}$ is productivity or knowledge, and $\mathrm{K}$ is human capital. Considering the Equation 1 and 2 the workforce is used both in product production $\left(\mathrm{L}_{\mathrm{y}}\right)$ and in research for innovations $\left(\mathrm{L}_{\mathrm{A}}\right)$. As such, the total labor force $(\mathrm{L})$ consists of two components as shown in Equation 3:

$$
L_{Y}+L_{A}=L
$$

In these models, the labor force employed in $\mathrm{R} \& \mathrm{D}$ is related to the rate of growth of technical knowledge. Romer and others assume that the size of the workforce is constant, so the economy is in a stable position, following the path of equilibrium growth when the share of the labor force employed in R\&D is constant. In this growth path, the per capita product and the ratio of capital to labor grow at the same rate, and these growth rates are equal to the growth rate of total factor productivity (Bazdar, 2011).

R\&D-related endogenous growth patterns have been proposed by economists such as Romer (1990); Grossman and Helpman (1991); Aghion and Howitt (1992) and Jones (1995). Romer's model is based on three logical hypotheses: 
1. Technological change is at the core of economic growth.

2. Much of the change in technology stems from the voluntary performance of people and economic agents, and this voluntary behavior stems from market motivation and profit. So technological change is endogenous.

3. Knowledge is fundamentally different from other economic goods because if we incur the cost of creating and assembling a knowledge once we can use that knowledge over and over again. In other words, the creation of new knowledge requires only a fixed initial cost.

In this model, any economy is assumed to have 3 sectors:

The first sector is the R\&D sector, which uses the human capital and volume of the existing knowledge to generate new knowledge, in particular as it presents plans for the production of new durable goods. The second sector is the intermediate goods sector which produces a large number of new durable goods using $\mathrm{R} \& \mathrm{D}$ and unused production plans that can be used in the production of final goods. The third sector is the production of finished goods sector, which employs labor, human capital, and a set of durable goods, to produce finished goods that can be either consumed or saved as new capital. Simple assumptions such as population stability, labor supply, and human capital marketed; R\&D use only of human capital and volume of knowledge and no depreciation are among the assumptions of this model. The production function in the final goods sector of this model is given by Equation 4:

$$
Y\left(H_{Y}, L, x\right)=H_{Y}^{\alpha} L^{\beta} \sum_{i=1}^{\infty} x_{i}^{1-\alpha-\beta}=H_{Y}^{\alpha} L^{\beta} \sum_{i=1}^{A} x_{i}^{1-\alpha-\beta}
$$

Where L, and respectively the labor force, the human capital and the capital goods used are in the production of the final goods. As can be seen, the function of production is homogeneous of degree 1. The difference between this production function and the conventional production function is that in this production function, the production technology is introduced directly into the production function through physical capital. Also, unlike the conventional production function, physical capital is made up of an infinite variety of durable goods.

Romer states that because of the symmetry in the model, all capital goods are presented at the same level, and thus shows the function of producing the final goods in Equation 5:

$$
Y=H_{Y}^{\alpha} L^{\beta} A \bar{x}^{1-\alpha-\beta}
$$

Where $\bar{X}$ represents the capital goods used in the production of final goods. Every durable commodity is produced by a producer who has exclusive rights in the intermediary commodities sector. The monopoly produces one unit of durable goods by purchasing a durable product plan from the R\&D department and applying $\lambda$ units of final goods. If firm $\mathrm{i}$ produces a unit of durable goods $\mathrm{I}$, it will lease them to firms producing finished goods at the price of $\mathrm{P}(\mathrm{i})$. Because of the depreciation in the model, the value of one durable commodity I is equal to the present value of the rental income that the commodity can generate over an indefinite period of time. Since firm $i$ is the sole seller of capital goods I, there will be a downward demand curve for that commodity that this downward demand curve is derived from maximizing the profits of firms in the finished goods segment. In this model, total capital is shown by Equation 6:

$$
\dot{K}(t)=Y(t)-C(t)
$$

Where $\mathrm{C}(\mathrm{t})$ and respectively represent total consumption at time $\mathrm{f}$ and changes in capital stock at time $\mathrm{t}$. Since the unit of consumption $\lambda$ is neglected to produce one unit of any durable commodity, then the size of $K$ can be related to the durable commodity actually used in production. So we can write Equation 7 :

$$
\mathrm{K}=\lambda \sum_{i=1}^{\infty} x_{i}=\lambda \sum_{i=1}^{A} x_{i}
$$

As can be seen in Equation 7, unlike $\mathrm{L}$ and $\mathrm{H}$, which are assumed to be constant, $\mathrm{K}$ grows on the basis of neglected consumption. The process of accumulating new designs (A ( $t)$ ) also depends on the amount of human capital allocated to the R\&D department and the available knowledge inventory. So the following equation can be written for the R\&D department:

$$
\dot{A}=\delta H_{A} A
$$

Where the total human capital employed in the R\&D sector is A, the available knowledge economy of economics and the efficiency parameter. As can be seen in relation (8), the production of new designs is a linear function of the human capital employed in the R\&D sector and the volume of existing knowledge. The linearity of relation (5) to A indicates unlimited knowledge growth. It also has two implications: one is that the use of more human capital in the R\&D sector leads to a higher production rate of new designs, and the second is that the greater the amount of knowledge available, the higher the productivity of the human capital in the R\&D sector (Ketabforoush et al., 2013).

After producing a plan and submitting bids from suppliers, the plan is sold to a firm that offers more. According to Romer, the price comes from Equation 9:

$$
P_{A}=\frac{\alpha+\beta}{r}(1-\alpha-\beta) H_{Y}^{\alpha} L^{\beta} \bar{x}^{1-\alpha-\beta}
$$


According to Equation 9 households also decide on consumption and savings with a given interest rate to achieve maximum utility. At the general level, they are linked by $\mathrm{H}=$ indicating that households provide a constant amount of human capital.

Romer believes that long-run equilibrium occurs when variables A, K, Y and C grow at the same constant rate. Romer also argues that in the long run, human capital payments will be equal in both R\&D and production of finished goods. So in the long run equilibrium, we can consider the Equation 10:

$$
W_{A}=W_{Y} \Rightarrow P_{A} \delta A=\alpha H_{Y}^{\alpha-1} L^{\beta} A \bar{x}^{1-\alpha-\beta}
$$

Where $P_{A}$ shows the price of the plan purchased by the monopolist, which is obtained from the Equation 9. By inserting $\mathbf{P}_{\mathbf{A}}$ from relation (9) to relation (10) we will have:

$$
H_{Y}=\frac{\alpha}{\delta(1-\alpha-\beta)(\alpha+\beta)} r
$$

As can be seen, in long-term equilibrium, $\mathrm{H}_{\mathrm{Y}}$ is constant. Considering $\mathrm{H}=\mathrm{H}_{A}+H_{Y}$ we can say that in long-term, $\mathrm{H}_{\mathrm{A}}$ is also constant. Thus, by considering Equation 8, it grows in long-term equilibrium state $\mathrm{A}$ at a constant $\delta H_{A}$ rate. Romer also shows that in long-term equilibrium, $\mathrm{K}, \mathrm{Y}$ and $\mathrm{C}$ also grow at a constant $\delta H_{A}$ rate. Therefore, in the long run equilibrium, the equilibrium growth rate can be considered as follows in Equation 12:

$$
g=\frac{C}{C}=\frac{P}{Y}=\frac{K}{K}=\frac{A}{A}=\delta H_{A}
$$

Considering Equation 11 and the limitation of $\mathrm{H}=H_{A}+H_{Y}$, one can also say the equilibrium growth rate in terms of interest rate $(r)$ is as following:

$$
g=\frac{C}{C}=\frac{P}{Y}=\frac{E}{K}=\frac{A}{A}=\delta H_{A}=\delta H-\frac{\alpha}{(1-\alpha-\beta)(\alpha+\beta)} r
$$

According to Equation 13, Romer presents the following results:

In the long-term, as human capital employed in the R\&D sector increases, economic growth rates increase, thereby creating a strong link between $\mathrm{R} \& \mathrm{D}$ allocation and economic growth rates.

The human capital opportunity cost of working in the R\&D sector is equivalent to the income that can be generated in the final product sector. The return on human capital employed in $\mathrm{R} \& \mathrm{D}$ is also equivalent to the present value of the net income that a plan will generate in the future. So if the interest rate is higher, the present value of net income would be lower, and then less human capital would be allocated to the R\&D sector, which would subsequently lead to a lower equilibrium growth rate (Romer, 1990). Grossman and Helpman (1991) and Aghion and Howitt (1992) also predicted a strong positive relationship between R\&D investment and economic growth in their endogenous growth models. Also in Jones (1995) he argues that greater R\&D spending only leads to higher production levels and does not meet faster long-term growth.

Coad and Grassano (2019) in study examined the effects of R\&D on Firm growth by using SVAR ${ }^{1}$ method. The results indicate that there is a mutual relationship between R\&D spending and economic growth. The results of the study also emphasize that policies to increase R\&D should be implemented to increase economic growth.

Blanchard and Olney (2017) studied effects globalization and human capital investment on economic growth in 102 countries by using panel data method. The results show increasing the amount of investment in human development can have positive effects on economic growth in countries.

Ketabforoush et al. (2015) studied the impact of R\&D and human capital on Iran's export in the period 1975 to 2012 by using OLS method. The results of study determined R\&D spending has a positive impact on Iran's export during the period under review.

Heath and Mobarak (2015) examined the impacts of new employment opportunities on improving employment, marriage and economic growth in Bangladesh's industry. The results show that new job opportunities can be an effective factor in economic growth and can change the living conditions of employed people.

Alinejad, Ghanavati, and Gharakhan (2012) have evaluated R\&D and the role of these costs in economic development. The results show that $\mathrm{R} \& \mathrm{D}$ at the country level and innovation management at the organization level have a positive and significant impact on achieving economic growth. According to the results, special attention should be paid to the innovative management of different organizations and institutions in order to achieve economic growth.

${ }^{1}$ Structural Vector Auto regressions 


\section{Statistics and Methods}

\subsection{Data and Statistics}

The research population of this study included 15 selected OECD countries including Australia, Austria, Belgium, Denmark, Finland, Hungary, Ireland, Italy, Japan, Netherlands, New Zealand, Poland, Sweden, United Kingdom and the United States of America. The studied period is 2012 to 2018. Time series data from these countries were collected from WDI (2018) and the OECD statistics site. The model presented in this study is shown in Equation 14:

$$
\text { Growth }_{i t}=\alpha+\beta_{1} \ln \left(G D P_{i t-1}\right)+\beta_{2} \ln \left(R \& D_{i t}\right)+\beta_{3} \ln \left(T A X_{i t}\right)+\beta_{4} \ln \left(L_{i t}\right)+u_{i t}
$$

Growt $_{i t}=$ Gross Domestic Product Growth Rate of i country.

$\ln \left(G D P_{i t-1}\right)=$ The logarithm of GDP of the last year of the i country.

$\ln \left(R \& D_{i t}\right)=$ The logarithm of $R \& D$ costs of the i country.

$\ln \left(T A X_{i t}\right)=$ The logarithm of taxes in i country.

$\ln \left(L_{i t}\right)=$ The logarithm of total number of people over 15 years old to total population of the i country.

\subsection{Model and Estimation Method}

The generalized method of moments (GMM) is estimated based on dynamic panel-data model. Arellano and Bond (1991) and Arellano and Bover (1995) have developed this method. This method uses two sets of cross-sectional data and time series data. This method solves the problem of endogenous explanatory variables. In this method, the dependent variable enters the model with a delay period as the explanatory variable. Dynamic relationships are modeled by the presence of the intermittent dependent variable among the explanatory variables (Abrishami, 2006). The GMM estimation can be done in two ways: first differences and orthogonal deviations. There are many advantages to using this method for estimating the model. For example, Beck, Levine and Loayza found the use of this estimate to be very useful for solving the variance of time series data. One of the benefits and applications of integrated data is better understanding of the dynamics by the researcher. Therefore, to understand the dynamics, one has to resort to the two-stage estimation methods (2SLS) of Anderson and Hsiao or the Arellano and Bond (1991) generalized method of moments. According to Matyas and Sevestre, estimating 2SLS may give large variances to the coefficients due to the difficulty in selecting tools, and the estimates are not statistically significant, so GMM method was proposed by Arellano and Bond (Ketabforoush et al., 2013). The tests used in the GMM method are the Wald and Sargan tests. The Wald test is used for simultaneous significance of regressors. This test has a $\chi^{2}$ distribution (chi-square) with degrees of freedom equivalent to the number of explanatory variables minus the constant component. The null hypothesis of this test assumes that all coefficients are zero. If the null hypothesis is rejected, the significance of the whole model is confirmed. In the GMM method, it is used as a GMM estimator to eliminate the correlation of the dependent variable with the error term and the error term. In addition, the compatibility of GMM estimators also depends on the validity of the tools used. To test this, we use the statistics proposed by Arellano and Bond (1991) and Arellano and Bover (1995) which tests the name of Sargans to measure the total validity of the tools used.

\section{Empirical Analysis}

Table 1 shows the results of the research on R\&D costs and its impact on economic growth by GMM method.

Table-1. Results of the estimation of the effect of R\&D on economic growth by GMM method as first difference.

\begin{tabular}{c|c|c|c}
\hline Variables & Ratio & T statistic & Probability \\
\hline GROW(-1) & 0.7086 & 9.9048 & 0.0000 \\
\hline LGDP & 0.1153 & 7.5668 & 0.0000 \\
\hline LR\&D & 0.2836 & 4.1666 & 0.0001 \\
\hline LL & 0.0036 & 10.5451 & 0.0000 \\
\hline LTAX & 0.0677 & 1.9013 & 0.0603 \\
\hline Wald test statistic & 723.9050 & & 0.0000 \\
\hline Sargan test statistic & 7.5299 & & 0.3208 \\
\hline
\end{tabular}

The data for parent and sargan test are presented in the table. As the results in Table 1 show, all coefficients are theoretically consistent, and all coefficients are meaningful except tax. According to the results, one-unit increase in GDP growth with a one-time lag and one percent of real GDP last year, R\&D, employment and taxation resulted in 0.708, 0.155, 0.228, 0.003 and 0.067 units of increase in the economic growth of the studied countries respectively. Also, the Wald test is used to examine the significance of the whole model. According to the P-Value of this test, the significance of the whole model is confirmed. The 
Sargan test statistic has a $\chi 2$ distribution (chi-square) with degrees of freedom equal to the number of exceedingly specified constraints and the null hypothesis of this test is that the tools are not correlated with the disruption components. By examining the P-Value of this test, the results imply that the estimation assumptions are valid (independent of the regressors including disruption), i.e. the instruments have the necessary validity, thus validating the results for interpretation.

In the estimation of the model by GMM method, in addition to the first difference, the model is also estimated as orthogonal deviations. Table 2 shows the results of estimating the effect of R\&D on economic growth of selected OECD countries using GMM method as orthogonal deviations.

\begin{tabular}{c|c|c|c}
\multicolumn{2}{c}{ Table-2. The results of the estimation of the effect of R\&D on economic growth by GMM method as orthogonal deviations. } \\
\hline Variables & Ratio & T statistic & Probability \\
\hline GROW(-1) & 0.7183 & 5.7625 & 0.0000 \\
\hline LGDP & 0.0998 & 6.5431 & 0.0000 \\
\hline LR\&D & 0.2627 & 4.2686 & 0.0001 \\
\hline LL & 0.0032 & 6.7590 & 0.0000 \\
\hline LTAX & 0.0739 & 2.1263 & \\
\hline Wald test statistic & 426.0694 & \multicolumn{2}{|c}{0.0000} \\
\hline Sargan test statistic & 4.5299 & \multicolumn{2}{|c}{0.6766} \\
\hline
\end{tabular}

Statistics on Wald and Sargan tests are also presented in the table. According to Table 2, the results of GMM model estimation in the form of orthogonal deviations are in line with the results of the first estimation, and all variables have theoretical basis. Based on the results of the Wald test, the whole model validity and reliability of the estimated coefficients are confirmed and also, based on the P-Value of Sargan test, the tools are valid and the results are validated for interpretation.

\section{Conclusion}

R\&D costs and technology advances reduce costs, increase productivity, and increase exports. New technologies will enhance the shift of production factors and create greater diversity in production. In addition, technology changes the relative cost of production and increases the relative advantage of firms and ultimately countries. Expenditure on $R \& D$ and new technologies and technologies allow businesses to upgrade their productive capacity, leading to increased capacity, reduced costs, increased quality and increased speed of delivery. The salient feature of ideas and innovations is that they are not competitive. For example, by adopting a new method, others can easily apply it. This has prevented the primary users from doing so. This feature creates external benefits that reflect the conditions of rising returns to scale and non-competitive markets. Of course, if producers can restrict the use of innovations and new ideas (such as patents), the degree and extent of their external benefits will be reduced. The purpose of this study was to investigate the effect of $\mathrm{R} \& \mathrm{D}$ spending on economic growth. In this regard, the impact of $\mathrm{R} \& \mathrm{D}$ on economic growth in 15 selected OECD countries was investigated by GMM method during 2012-2018. The results showed that R\&D spending had a positive and significant effect on economic growth. Last year's GDP, exchange rate and tax also had a positive impact on economic growth.

\section{References}

Abrishami, H. (2006). Applied econometrics. Tehran: Tehran University Press.

Aghion, P., \& Howitt, P. (1992). A model of growth through creative destruction. Econometrica, 60(2), 323-351. Available at: https://doi.org/10.2307/2951599.

Aghions, P., \& Howitt, P. (1998). Endogenous growth theory. USA: MIT Press.

Alinejad, M., Ghanavati, E., \& Gharakhan, T. (2012). Evaluating RछD expenditures and the role of these expenditures in economic development. Paper presented at the A Regional Conference on New Issues in Accounting.

Arellano, M., \& Bond, S. (1991). Some tests of specification for panel data: Monte Carlo evidence and an application to employment equations. The Review of Economic Studies, 58(2), 277-297. Available at: https://doi.org/10.2307/2297968.

Arellano, M., \& Bover, O. (1995). Another look at the instrumental variable estimation of error-components models. Journal of Econometrics, 68(1), 29-51. Available at: https://doi.org/10.1016/0304-4076(94)01642-d.

Arrow, K. (1962). Economic welfare and the allocation of resources for invention, a chapter in the rate and direction of inventive activity. Economic and Social Factors, 609-626 from National Bureau of Economic Research, Inc.

Barro, R. J. (1990). Government spending in a simple model of endogeneous growth. Journal of Political Economy, 98(5, Part 2), S103-S125. Available at: https://doi.org/10.1086/261726.

Bazdar, P. (2011). Analyze the role of R \& D on the development of the transport sector in Iran using endogenous and exogenous growth patterns. Transportation Bulletin, 2(2), 115-132.

Becker, G., Murphy, K., \& Tamura, R. (1990). Human capital, fertility, and economic growth. Journal of Political Economy, 98(5), $12-37$.

Blanchard, E., \& Olney, W. W. (2017). Globalization and human capital investment: How export composition drives educational attainment. Journal of International Economics, 106(3), 165-183. Available at: https://doi.org/10.1016/j.jinteco.2017.03.004. 
Coad, A., \& Grassano, N. (2019). Firm growth and R\&D investment: SVAR evidence from the world's top R\&D investors. Industry and Innovation, 26(5), 508-533.

Grossman, G. M., \& Helpman, E. (1991). Quality ladders in the theory of growth. The Review of Economic Studies, 58(1), 4361. Available at: https://doi.org/10.2307/2298044.

Grossmen, G. M., \& Helpman, E. (1989). Product development and international trade. Journal of Political Economy, 97(6), 1261-1283.

Heath, R., \& Mobarak, A. M. (2015). Manufacturing growth and the lives of Bangladeshi women. Journal of Development Economics, 115, 1-15. Available at: https://doi.org/10.1016/j.jdeveco.2015.01.006.

Hunermund, P., \& Czarnitzki, D. (2019). Estimating the causal effect of R\&D subsidies in a Pan-European program. Research Policy, 48(1), 115-124. Available at: https://doi.org/10.1016/j.respol.2018.08.001.

Jones, C. I. (1995). R\&D-based models of economic growth. Journal of Political Economy, 103(4), 759-784.

Ketabforoush, B. A., Dizaji, D., Salavati, K., \& Gholami, S. (2013). Investigating the impacts of innovation and RED on increased value for agriculture. Paper presented at the Second National Conference on Sustainable Agriculture and Healthy Environment. Hamadan, Iran.

Ketabforoush, B. A., Yahyavi, R., \& Pourebrahim, M. (2015). Examining the effects of R\&D and human capital on export of Iran. The Open Access Journal of Resistive Economics, 3(4), 103-115.

Lucas, J. R. E. (1988). On the mechanics of economic development. Journal of Monetary Economics, 22(1), 3-42.

Molayi, A., \& Dehghani, A. (2011). Assessing the impact of research and development costs on market share in Iranian industry sector (LSTAR Nonlinear Approach). Journal of Economic Growth and Development, 1(4), 55 -74.

Romer, P. M. (1990). Endogenous technological change. Journal of Political Economy, 98(5, Part 2), S71-S102.

Rosenberg, N. (1982). Inside the black box: Technology and economics. Cambridge: Cambridge University Press.

Schumpeter, J. A. (1934). The theory of economic development. Cambridge, Mass: Harvard University Press.

Shakeri, A., \& Ebrahimi, T. (2009). The impact of research and development expenditures on inventions and economic growth (Comparative Analysis between Developing and Developing Countries). Journal of Knowledge and Development, $17(29), 1-40$.

Solow, R. M. (1956). A contribution to the theory of economic growth. The Quarterly Journal of Economics, 70(1), 65-94.

WDI. (2018). World development indicators: World Bank. 